\title{
A Review Of Common And Quick Tests In Executive Function In Adults With Neurological Disorder
}

Fateme Satarian, Zahra Ghoreishi, Shohreh Jalaei

Purpose: As a higher cognitive function is controlled Executive function by frontal cortex. It is consisted of Decision-making splanning inhibition rorganization and working memory. According to high prevalence of executive dysfunction in adults with neurological disorders such as Dementia and stroke and considering to applying appropriate tests in neurological patients and aging people in order to diagnose executive dysfunction quickly and correctly ،In this study we aimed to review common and quick executive function tests.

Methods: This research was a review study on common and quick executive function tests in adults. A search was conducted using some databases including Iran medex ‘SID ،Magiran ،Google scholar ، M edline ،Science Direct ،Scopus and Web of Science. The tests were investigated regarding to the date of publishing rmethod of administration starget populations ssubscales stime administration and psychometric features.

Results: According to inclusion and exclusion criteria of this study 'we found 26 common and quick tests ' $M$ ost of them were in English and just one of them was a Persian version. Thirteen tests of them were translated or modified version of original English test. Ten tests of them were very quick with average administration time about 10 minute and the other need 30 minute to administer.

Conclusion: Regarding to importance of evaluating of executive function in neurological patients especially individuals with Dementia beside existence of a lot of tests in other languages and lack of quick executive function tests in Persian, results of current study can help neurologist, speech and language pathologist and other experts to be familiar with common quick tests and their clinical application. These results also recommend researchers and clinicians to translate and adapt some of the quick and easy administer Executive function tests in Persian.

Key words: executive dysfunction rassessment tests rneurological disorder 'Deficient in executive function

DOI: $10.7575 /$ aiac.abcmed.ca1.25

A I Published Date: February 2017

Peer-review is under responsibility of the 9th Iranian Stroke Congress.

Published by Australian International Academic Centre, Australia

This published work is open access under the CC BY license.

Available online at www.abcmed.aiac.org.au 